

\section{An Extra Care community's perceived priorities for 'whole system' relationships: A Q-methodological study}

\begin{tabular}{|r|l|}
\hline Journal: & Health \& Social Care in the Community \\
\hline Manuscript ID & HSCC-OA-16-0170.R2 \\
\hline Manuscript Type: & Original Article \\
\hline Keywords: & $\begin{array}{l}\text { Relationships, Q-Methodology, Action Research, Extra Care Housing, Health } \\
\text { and Social Care, Ageing }\end{array}$ \\
\hline \multicolumn{2}{|l}{} \\
\hline
\end{tabular}

\section{SCHOLARONE ${ }^{\text {M }}$}




\section{Abstract}

Health and social care settings world-wide need to sustainably improve the quality of relationships across communities or 'whole systems'. This research informs the development of a relational framework based on stakeholder perspectives. It is grounded in an action research project with practitioners, and draws on a previous literature review, to present the underpinning elements of quality relationships as statements, organised under the headings of integrity, respect, fairness, compassion and trust. Using Q methodology, 27 participants, comprising a range of stakeholders (staff, residents, family and service providers), rank-ordered 48 statements based on perceptions of the importance of differing aspects of relationships. By-person factor analysis was used to create five factors or viewpoints by comparing and contrasting using the composite rankings alongside interview data collected for each participant. The first view 'Altogether now' prioritises compassionate engagement. Secondly, 'Respect is a two way street' emphasises the need for reciprocal respect and recognition of history. The factor labelled 'Free spirits' posits the dominant view of freedom. The fourth view 'Families... strengths and challenges' focusses on the necessary and complex involvement of families and finally, 'Helping hands' emphasises the role of relationships in increasing previously low expectations of social integration for previously isolated residents. The different views that exist on the composition of quality relationships can be used to help extra-care communities to understand and utilise relationships as a powerful and effective resource.

Keywords: Relationships, Q-Methodology, Action Research, Extra Care Housing, Health and Social Care , Ageing

\section{What is known about this topic?}

- There are increasing global challenges in relation to the socio-economics of ageing populations and the humane care of older people

- Positive human relationships and attributes that underpin them are a vital system-wide component of humane care for older people

- Extra-Care housing provides opportunities to draw upon community wide relationships to improve conditions across stakeholders

\section{What this paper adds}

- A 'system-wide' framework examines subjective views on developing high-quality relationships in an Extra-Care facility

- Five distinct factors were derived from the $Q$ sort indicating the range of differing perspectives on developing the relational environment

- The work outlines how a relational framework combining the highlighted statement set and resulting factors can be used to monitor relational quality 


\section{Introduction}

Across the world, people are living longer, creating a shift in the socio-economic balance between older and younger generations (United Nations, 2013). This change is accompanied in many OECD countries with; welfare spending cuts and cost rises (Robertson et al., 2014), increasingly complex patient and user needs and a growing emphasis on the integration of services provided by differing models of public and private sector engagement (Humphries and Curry, 2011; NHS, 2014; English Health Service Ombudsman, 2011). Such pressures on health and social care systems are compounding to create a burgeoning delivery gap in older people's housing, care and support. However, a range of evidence now exists, which indicates that the improvement of stakeholder relationships, both within and between communities, holds significant potential for improving health and social care delivery.

The social determinants of individual health are well established (World Health Organisation, 2010) and reflected in the international evidence of health buffering effects available through social connectivity and activity, contributing to an increase in available resources and a decrease in social isolation (Derose $\&$ Varda, 2009). These networks of relations have a direct influence on community health through reciprocity, inter-dependence and family support (Antonucci et al., 1990; Smith \& Christakis, 2008; Chen et al, 2014). For older adults, research indicates the influence of social support on improved physical and mental health and longer living across cultures (Fiori et al., 2008).

Alongside health benefits, the underlying quality of relationships is fundamental to management and delivery of health and social care across systems (Gilson, 2003/2006; Calnan \& Rowe, 2006/2008; McCabe \& Sambrook, 2014; Pattison \& Kline, 2015), yet management often focus on considering only discrete parts of a system and not inter-relations between stakeholders (Plsek \& Wilson, 2001; Peters, 2014). The beneficial potential of considering relationships within and between health and social care communities can be seen through both positive and negative outcomes.

Powell et al (2014) indicates how positive organisational relationships, underpinned by elements such as fairness and shared decision making, can have an important role in care outcomes. However, relational breakdown amongst stakeholders can have the reverse influence. For example, at the institutional level it is well established that a lack of trust in relationships between healthcare providers and communities negatively influences health seeking behaviour (Mechanic, 1996; Mohseni \& Lindstrom, 2007). In the UK, Francis (2013) highlighted how a lack of consideration of the impact of organisational restructuring on the strategic relations between different bodies led to a serious deterioration of care delivery. In the housing care sector, a breakdown in relations 
between users and providers has been directly related to institutional abuse (Care Quality Commission Review, 2014) and relational failings between different agencies, families and external stakeholders has led to neglect (Corkhill, 2014).

\section{Frameworks and tools for measuring relationships}

Whole-system approaches to help provide seamless provision of health and social care are increasing (Kodner, 2006) and frameworks that help gather relationship-focussed data across systems of stakeholders groups are needed to assist leaders and commissioners in making better strategic decisions based on relationships and connectivity (Turnbull, 2011).

Relational Coordination (Gittell \& Douglass, 2012) is an example of a management tool developed to enable systemic measurement of relationships, with extensive use in healthcare (Gittell et al., 2000/2008/2013). Relational Coordination emphasises the positive elements of social integration expressed through co-ordination between different teams and disciplines by focusing on perceived levels of respect, problem solving, and the nature and frequency of communication between different roles. Emerging from the US context the approach provides some indication of the quality of underlying relationships but is primarily based on tasks and the roles of staff and does not directly account for all stakeholders within the system.

\section{Relationships in extra-care}

Extra-Care housing (ECH) emerged in the UK as an approach to housing, care and support founded on principles of choice and control (Department for Communities and Local Government, 2008), and aimed at reducing the burgeoning cost of care whilst simultaneously managing the diverse needs of an ageing population (Riseborough et al., 2015). Distinctive features include; housing separate from care, secure and purpose built units that promote independence and 'progressive privacy', secure tenancy rights, controls over access, available office space for management and the wider community, communal space and facilities, 24 hour care, and use of assistive technology (Riseborough et al., 2015:4). People moving into extra-care facilities tend to be younger and suffer from less physical and cognitive impairment (Darton et al., 2012).

The potential for ECH to improve social well-being of residents has been widely discussed (Evans and Vallelly, 2007; Callaghan, 2008; Callaghan, Netten \& Darton, 2009; Orrell et al., 2013). In a whole system view (Lewin, 1946) stakeholder relationships will have a significant role to play in leveraging any social well-being impact of the increased independence associated with ECH. 


\section{The research project}

The work was undertaken in collaboration with an industry partner, specialising in strategic whole systems analysis. An action learning approach was adopted and provided two advantages. Firstly, it is congruent with conceptualising communities of stakeholders as whole systems in that to understand or to predict behaviour, the person and his environment have to be considered as one constellation of interdependent factors' (Lewin, 1946:338). Secondly, it promotes the acceptance of knowledge from all areas of the research context e.g. practice, research and policy are treated equally in shaping findings (Meyer, 2000).

The two objectives of the paper are; (a) to build a set of 'system-wide' relational statements for $Q$ method subjective analysis, across extra-care stakeholders and (b) to develop perspectives (factors) from this work that when combined with the derived statement set can be used as a framework to sustainably and humanely consider system-level relational quality across extra-care communities.

\section{Methods}

This study follows a Q Methodology (Stephenson, 1953) design that seeks to operationalize subjective views around a shared topic of interest (Brown, 1980). Q method extracts patterns of meaning from multiple responses to a given set of statements (known as the concourse). The two basic components of $Q$ methodology are the $Q$ sort procedure and the by-person factor analysis. Q methodology has particular utility in health and social care due to; its appropriateness in complex social situations where professional and user perspectives differ, and where evidence is drawn from a wide base (Stainton Rogers, 1991), where there is a need to include the marginalized (Brown, 2006), and a robust qualitative technique is required (Cross, 2005). Divergent areas of H\&SC research using Q methodology include: pain (Eccleston et al., 1997); mental health and housing (McCauley et al., 2015); health lifestyles (van Exel et al., 2006); quality of life (Stenner et al., 2003); economics of health choices (Baker, 2006); team working (Buljac-Samardzic et al., 2011); risk training (McKeown et al., 1999) and nursing practice (Clarke \& Holt, 2015) .

The work was conducted through the four recognised stages of statement development - selection of a sample of respondents, statement ranking, analysis, and interpretation (Buljac-Samardzic et al., 2011). Full ethical approval for this work was sought and awarded by the University of Leeds Research Ethics committee (SHREC/RP/519) and support provided by the local Clinical Commissioning Group overseeing the new ECH development. 
Development and selection of statements - Q Set

To develop the statements this research drew on both extant journal literature, akin to Brown (2006), and practitioner perspectives, to identify underlying behaviours, practices and processes that might support 'quality' community wide relationships within an extra-care setting identified in a scoping literature review (Grimshaw et al., 2016). This material was used by researchers and practitioners $(n=5)$ to derive and organise statements into five themes of integrity, respect, fairness, compassion and trust. For example, it is understood that inclusive decision making is a key component of a fair process both organisationally (Cohen-Charash \& Spector, 2001, Colquitt et al., 2001) and within care settings for residents (Knight et al., 2010) hence the inclusion of the statement Residents know why decisions that affect them are made, placed under the fairness theme (statement No. 34 in Table 2). Finally, to complete the initial framework and to ensure the 48 statements were spread across the 'whole system' of the organisation, statements were also positioned under four socio-technical (Davis et al., 2014) headings of culture, people, process, and infrastructure (inc. physical and technology space). Mapping the statements in this way enables further analysis of the emergent factors.

\section{Justification of sample size \& selection of participants - P set}

Q methodology studies do not require formal power calculations to determine the number of participants. However, Kline (1994) suggests a ratio of 2:1 (statements to participants). A pilot study was conducted with 3 elderly participants to check for face validity of the statements and also to ensure the process was suitable for elderly participants in terms of timing, scale and topic. A total of 6 statements were changed and/or removed due to overlapping or repetitive elements.

\section{Recruitment for the study}

The research included a range of stakeholders connected to the extra-care facility. We labelled these three groups as residents ( $n 7)$, people officially resident at the care home (the extra-care unit completed its own formal assessment of new residents and this informed the choice of residential participants); staff (n5), anyone employed specifically by the care home, and stakeholders (n15), people who have a relationship with the care home but are not employed directly e.g. family members or additional service providers e.g. facilities staff, social workers. The aim was to ensure the widest possible range of participants from across the system, the rationale being that the level of contact and differing role and mode of connection with the care community may colour the views of the different groups. The age range of participants was between $26-90$ with $74 \%$ female. The selection of residential participants was conducted by random sampling of names and subsequent 
clarification discussions with the housing coordinator. Information sheets were included in all new residents' introductory packs for the care home. Posters were placed in the unit and staff and stakeholder participants were approached via researcher introduction at management meetings and introductory emails direct to all staff.

\section{Procedure - Ranking of the statements}

Firstly, participants were asked to complete an informed consent form and then presented with a pack of shuffled cards ( $n 48$ ) with statements ( $Q$ set) printed on them and asked to arrange these cards on a pre-defined grid pattern. The statements were placed in response to a single over-arching question "In order to have the best possible relationships within an extra-care housing community it is important that...". Statements were arranged on the basis that each person subjectively believes each statement is more or less important to them (See Figure 1). The statements were ranked on a dimension of +5 to -5 depending on subjective view of importance. The completed pattern represents an individual $Q$ sort (n27).

\section{Interviews}

Interviews with participants are an important but under used component of the q sort method (Brown, 1980:200). They are useful for integrating participant perceptions into the theory and thematic development and enhance "interpretation of the factor array to be based on the participants' perceptions and attitudes to the phenomenon under study" (Gallagher and Porock, 2010: 296). This work follows the example of Stenner et al (2003) by integrating comments to support the presentation of each factor.

Interviews were conducted before and after statement ranking in order to capture (a) anything that is missing that people would have liked to have seen added, (b) more detail on items at the extreme points of the sort or the transition points from positive to negative, and (c) any items of confusion or needing further clarification. Interviews were 40-90 minutes in length and took place on-site at the extra-care housing facility less than six weeks from the time of opening, and were conducted over an eight week period between August and October 2015. All interviews were captured on a voice recorder and transcribed verbatim.

\section{Findings: Q-Analysis}

The mode of analysis in Q Methodology is to attempt to explain the overall configurations and the common patterning and arrangement between respondents $Q$ sorts by factor analysis. $27 \mathrm{Q}$ sorts were entered into PQ Method (Schmolck, 2002) for analysis. The first stage of Q-analysis is the calculation of correlations between all the item scores for each $Q$ sort. Factor analysis is then applied 
to the data matrix. The centroid analysis method ( Brown (1993)) was used to derive the factors, and varimax rotation was used to reveal the different groups loading on each of the extracted factors.

The choice of how many factors can be chosen for rotation was based on balancing three aspects: (a) an explanation that accounts for the maximal amount of variance explained by the extracted factors (Watts and Stenner 2005), (b) had a minimum of $2 \mathrm{Q}$ sorts loading on each of the factors alone (Brown 1980) (see Table 1), (c) results that provided the most useful theoretical explanation by reference to the 'whole' response set. The optimal number in this case based on the above conditions was a 5 factor explanation. Eigen values were all above the $1 \%$ minimum required for all factors with a total of 12.13 . The 5 factors had 26 participants loading significantly with $52 \%$ variance $(24,8,8,6,6 \%$ percentage variance respectively). Scores of between $35-40$ are viewed as a sound result (Kline, 1994), thus enabling further analysis. There was one non-significant QSort (See Table 1).

\section{INSERT TABLE $1 \& 2$ here}

\section{Interpretation of factors}

The analysis revealed 5 relevant factors. These 5 factors are presented in turn using factor scores differentiating statements, combined with qualitative quotes from the participants. Interpretation of the factors is assisted by examining those statements that are distinguished by position at points of most and least agreement between the factors and those factors that are statistically significant in distinguishing each factor from the others. The factors are arranged in order of variance Brackets() indicate statement number and [] participant.

\section{Factor 1 Unity: 'Altogether now'}

The majority of participants loaded on this factor and prioritised compassion statements, expressing a need to focus on the whole person (28) as the basis of the relational environment between staff and residents [P5] " if someone is in a wheelchair...they have got other things too and they can do activities, they can still feed themselves..hold a conversation...lead an activity, you're not just seeing them in a wheelchair...you've got to see that they've had a life, what they've done...". Empathy within relationships between staff members, focussing on understanding the pressures of fellow professionals, was seen as important in order to reach workable compromises around providing the best possible environment for residents. 
Compassion in relations was also strongly connected with fairness and being treated as equals (33) [P5] "nobody's any different in here, whether they're in a wheelchair, they're bed bound, they're up and walking around, they're still the same person". People loading on this factor viewed residents seeing the same staff everyday (8) as an important mechanism for expressing compassion [P28] "We do need continuity of staff that's coming in. We have the service users getting used to one person, then they'll take them off... send somebody else in who's got to learn all about that person again and it unsettles people, it unnerves them" and this continuity of relation was directly connected to trust building [P17] “[before moving in] it was different carers coming in all the time, so my mam didn't trust them, she's spitting tablets out, and this is part to do with the dementia". Compassion and empathy statements were viewed as central within this factor to unlocking successful relationships.

\section{Factor 2 Reciprocal relationships: 'Respect as a two-way street'}

People loading on this factor were predominantly external stakeholders, and expressed the need for reciprocation moderated through respect for the individual as a key component for establishing a healthy relational environment. 'Seeing the current and past potential of residents as important life achievements recognised by others' (45), and 'an opportunity to contribute skills and knowledge' (46) were important. 'Age is respected' (44) was also placed higher than in the other factors which largely negated age as an issue and a barrier to fairness. Here it was viewed as important not just from the position of elders naturally deserving respect, but also that younger people in the community may have different needs that need to be respected. The external stakeholders that loaded on this factor proposed respect for the individual in general as a guiding perspective [P26] "working in the industry for so long, you know, it's always been....to treat the person with respect and as an individual".

Factor 3 Free spirits: “I'm free”

The statement suggesting a need to have regular access to the internet or phone (42) was viewed as most important when related in part to the need to connect more meaningfully with the boundaries beyond the unit and not be constrained by personal or institutional boundaries. This was exemplified by one resident who was highly involved with developing ideas with communities outside the facility to introduce activities or events for other residents. [P27] “I've phoned [x] today ...to organise our day out and that, you know, and we had a meeting this morning so I said, "we'll do raffles and that [to] put the money towards like an outing for the residents". Free expression of emotions was a relatively higher (37) loading on this factor. Staff saw this as connected heavily to relationship development 'this is their environment, they should be able to say, [P19] "Oh well actually something's not right. I don't feel right" or, "I'm not happy with this member of staff," or 
something like that....and if they can't express their emotions, then I don't think that that's a good relationship'. Relatively low scoring of 'staff and residents having shared expectations of the future' (22) may also be suggestive of a need for freedom over cohesion. The statement 'People are prepared to give and take when they disagree' $(20)$ is associated here with compassion but viewed differently through this factor, as a possible restriction on free expression [P27] "Yeah, that's me, if you've got [anything] to say, say it to the face and that's it, and it's always been my motto... and that would be the end of it".

Factor 4 Connecting communities: "Families...strengths and challenges"

For staff loading on this factor, family members prioritised family influence through contact with staff, suggesting it is important that family get on well with staff (2) and that family continuity is an important part of relational development. For residents this was related to the nature of family in providing a strong secondary support role [P8] "I think it's important that my daughters can hold discussions with the people that care for me, or visit, I think it's very important". For staff, family involvement represented an instrumental need for a good relationship directly connected to helping new residents to make the transition and settle in (32) and this was seen as a vital time for establishing trust as the role of the family changes [P2] "families are giving up the full-time role of caring and this can make it a difficult time for them to adjust". Families were viewed by staff as crucial in this process but also potentially putting a lot of pressure on the system through multiple and divergent demands. For example, dealing with multiple family members makes the need for good relationships more important and challenging [P28] "different family members deal with it [process of care] differently and they look for different support within you. So in a way it's a real emotional drain because you're trying to take pressure off the family, off friends".

Factor 5 Enabling independence: 'helping hands'

People loading on this factor see that the facility infrastructure and processes should be designed to enable relationships that focus on developing the autonomy of the residents. They rated infrastructure statements that support autonomy higher than those more obviously relating to compassion or respect. For example, they rated more highly the need for residents to have a say over the local environment (21) and that they should be directly involved in the decisions that affect them (36) [P13] “somebody in my position I'm more independent so I wouldn't want people to make decisions for me that I don't know about" and how things get done around the unit (38). This was the case even when people may lack capacity to be fully engaged in the process [P19] "Especially with some people that are not, maybe not all there in their mind, but you've still got to treat them as if they [are] .....trying explaining to them, maybe, things in a different way, and don't lie to them". 
Direct involvement was viewed as more important than involving family and friends in decision making (31). [P9] "I can make me own decisions properly now, a rational decision whereas before I couldn't make a rational decision" [in previous environment]. In this factor, family can be seen here as an obstacle to independence; [P 26] "they [families] do take a lot of the independence off a person,.... they think they have good reason to, risk they might fall, they might harm themselves and, you know, we do disable the elderly" and [P 26] "Why are you letting my dad go out, he's not safe?" "Well, if he wants to go out, it's his choice" Respect for privacy (47) was also more important to this group, either seen as a fundamental principle "people respect each other's privacy....?..well...duh" [P26] [i.e. that's obvious] or as a reaction to a previous poor residential situation [P14] "before it was one constant worry about.... have you locked your door? [in previous accommodation]. We had notes literally stuck on the [front] door saying, do not open this door" [family member]. The relative negative emphasis on constantly helping people to feel at home (29) reinforced the view of the need for an autonomy based environment.

\section{Discussion}

The twin objectives of this study were the exploration amongst system-wide stakeholders of predefined statements reflecting a healthy relational environment in extra-care, and using the responses to inform a relational framework for use by health and social care leadership. The first objective was met by capturing the subjective views of 48 relational statements across an extra-care community to reveal patterns of meaning. The second objective was met by establishing factors that can be used to inform the pre-defined framework of statements (Table 2). Analysis of the sorted statements revealed five distinct perspectives emerging from across the stakeholder groups. Factor 1 'All together now' was the most loaded factor and occurred across all groups with a traditional emphasis on empathy, a key element underpinning compassion, as a driver for quality relationships within the community. Factor 2 'Respect as a two-way street' focussed on the need for recognition and achievement and was a view expressed predominantly from external stakeholders who had less contact with residents.

The third factor 'Free spirits' comprised predominantly younger and more outward facing residents who suggested they desired greater contact with the external community. People loading on Factor 4 'Families...strengths and challenges' were senior permanent staff and professional external stakeholders with decision making responsibilities. It could be noted these people have a strong sense of establishing cohesion across the whole system and may be more alive to the influence of others on the core relationships between staff and residents. The fifth factor, 'Helping hands' emerged predominantly from family members who had relatives that had arrived at the housing unit 
often from highly insecure and stressful environments. This factor also included a younger resident with a newly established desire for outward facing activity in the light of successful transition.

There were no clear consensus statements (statements with the same positioning across all factors) but the two in most agreement were 'Different people can take the lead when things go wrong' (1) which was viewed neutrally across all factors (i.e. placed centrally within the concourse) and the statement 'When something goes wrong someone is found to blame' (12) which was mostly considered as relatively less important across all factors. This low positioning of blaming is reflected in wider older adult research where the inverse of blame, forgiveness, is viewed as having important potential for acting as a social lubricant (Girard \& Mullet, 1997).

Risk was also largely viewed as of lesser importance by participants, including most staff, in respect of relationships. The extent that people will take positive risk (1) has capacity as an important component of building stronger inclusive communities (Morgan, 2013). For one participant this could only occur when assessed needs were fully met and then 'risks can be stretched without compromising [safety]' [P15]. However, on the whole people tended to interpret statement (1) in an almost wholly negative light and something that should be avoided. This reinforces the difficulty in overcoming entrenched and important perspectives e.g. all risk is bad, to support a more relationally focussed community, where managed risk can be constructive. The statement 'Peoples culture and traditions are respected' (48) was not viewed as relatively important in any of the five factors. This was reflected in interviews where people viewed the community to be homogenous (White/British). This statement may be viewed differently in other older care communities where black or minority ethnic groups are increasingly represented (Mold et al., 2005) and where culturally inappropriate care maybe a barrier to some ethnic communities service uptake (Jewson et al., 2003).

An additional contribution of this work was the highlighting of the impact on relationships of the evolving notion of extra-care, and the nature, limits and balance between independence and benevolent care. Ambiguities around the meaning of extra-care are well-known (Baker, 2006), and we observed how this influenced decision making amongst staff and stakeholders, specifically about when and how to intervene with residents. For example, one participant [1] saw these ambiguities as a barrier to trust forming, as clear routines were taking time to emerge that would then enable people to move beyond rigid rule following. Developing common perspectives of the extra-care concept on the ground becomes even more important in facilities with mixed communities where the needs of specific groups such as dementia sufferers may be neglected (O'Malley \& Croucher, 2005). 


\section{Research limitations}

The study was conducted with a variety of stakeholders from a single extra-care community in order to provide a framework which does not delineate between different communities e.g. residents and providers but seeks to find common ground. Caution must be used in generalising from results as the emphasis of $Q$ methodology is on establishing a population of viewpoints and not participants (Watts \& Stenner, 2005). The emerging social context in a new extra-care facility was chosen as a transition point when immersion into a new environment would make the nature of relationships, old and new, salient to everyone. A potential limitation of this approach was that there was an inevitable settling in period for new residents and staff. This emerged as of specific importance for those residents arriving from relatively impoverished or insecure environments. However, a survey for a larger and more robust framework can now be informed by the viewpoints expressed and captured in the factors based on a whole system perspective of key indicators that could be more readily compared across contexts.

The behaviours, processes and practices that underpin the statements come from a wide range of literature and have been co-created with the academic/practitioner group. However, what constitutes a quality relationship is complex so it is possible that relevant characteristics in relation to Extra-Care were omitted although the statements were cross checked with participants during the $Q$ sort procedure, and there were no additional attributes suggested that were not covered within the present statement set. People responded well to the process of sorting the statements, commenting that the process had helped them to think about relationships from the community perspective. Management of the facility also organised information sharing events for different stakeholders based on key findings.

Implications for practice

Management tools that can be usefully deployed to build, maintain, and enhance community level relations are rare (Collins, 2014), hence results here may be of interest to other care settings where a whole system view of relationships needs to be considered such as palliative care settings where strong and resilient relationships between providers and patients, families and work colleagues are at the core of the provision of service (Walshe \& Luker, 2010).

The five emergent factors, used in conjunction with the predefined statement framework (Table 2), may help management to consider strategies for managing community wide relationships. For example, a community that had a dominant 'free spirt' perspective amongst the community may neglect some of the more compassionate elements required to consider the needs of more 
disadvantaged groups. This could influence the recruitment of staff. For example, management might seek to consider the relational perspectives, based on the framework, before employing new staff as this may have an impact on care approaches across the system as a whole. For residents and families it might prove useful to consider the impact they have on the running of the facility through the way they seek to conduct their relationships and their preferences and expectations for relational behaviour as constituted under the five factors. For example, those requiring a preference for 'free-spirited' supporting relations could be assisted by staff who develop a less interventionist approach and employ managed risk strategies. 


\section{$\underline{\text { References }}$}

Antonucci, T. C., Fuhrer, R. \& Jackson, J. S. (1990) Social Support and Reciprocity - a Cross-Ethnic and Cross-National Perspective. Journal of Social and Personal Relationships, 7, 519-530.

Baker, R. M. (2006) Economic rationality and health and lifestyle choices for people with diabetes. Social Science \& Medicine, 63, 2341-2353.

Brown S.R. (1980) Political Subjectivity: Applications of Q Methodology in Political Science. Yale University Press, New Haven.

Brown, S.R. (1993) A primer on Q methodology. Operant Subjectivity, 16, 91-138.

Brown, S. R. (2006) A Match Made in Heaven: A Marginalized Methodology for Studying the Marginalized. Quality and Quantity, 40, 361-382.

Buljac-Samardzic, M., van Wijngaarden, J. D. H., van Wijk, K. P. \& van Exel, N. J. A. (2011) Perceptions of team workers in youth care of what makes teamwork effective. Health \& Social Care in the Community, 19, 307-316.

Callaghan, L. (2008) Social Well-Being in Extra Care Housing: An Overview of the Literature. PSSRU Discussion paper 2528. Downloaded from: http://www.pssru.ac.uk/pdf/dp2528.pdf (Accessed 19.01.2016.)

Callaghan, L., Netten, A. \& Darton, R. (2009) The development of social well-being in new extra care housing schemes. Joseph Rowntree Foundation. Downloaded from: https://www.jrf.org.uk/file/39996/download?token=ITzluT2A (Accessed 7.5.16)

Calnan, M. \& Rowe, R. (2006) Researching trust relations in health care. Conceptual and methodological challenges -an introduction. Journal of Health Organization and Management, 20, 5, 349-358.

Calnan, M. \& Rowe, R. (2008) Trust, accountability and choice. Health Risk \& Society, 10, 201-206.

Care Quality Commission (2014) An analysis of the Care Quality Commission's responses to events at Orchid View identifying the key lessons for CQC and outlining its actions taken or planned. Downloaded from: https://www.cqc.org.uk/sites/default/files/Orchid\%20View\%20Investigation\%20Report.pdf

Chen, Y., Hicks, A. \& While, A. E. (2014) Loneliness and social support of older people in China: a systematic literature review. Health \& Social Care in the Community, 22, 113-123.

Clarke, D. J. \& Holt, J. (2015) Understanding nursing practice in stroke units: a Q-methodological study. Disability and rehabilitation, 37, 1870-1880.

Cohen-Charash, Y. \& Spector, P. E. (2001) The role of justice in organizations: A meta-analysis. Organizational Behavior and Human Decision Processes, 86, 278-321.

Collins, A. (2014) 'Measuring what really matters: Towards a coherent measurement system to support person-centred care'. London: The Health Foundation. Downloaded from: www.health.org.uk/sites/default/files/MeasuringWhatReallyMatters.pdf (Accessed 19.01.2016.)

Colquitt, J. A., Conlon, D. E., Wesson, M. J., Porter, C. O. L. H. \& Ng, K. Y. (2001) Justice at the millennium: A meta-analytic review of 25 years of organizational justice research. Journal of Applied Psychology, 86, 425-445.

Corkhill, R. (2014) Multi-agency case audit: Agency responses to safeguarding concerns affecting residents at Purbeck Care Ltd, a registered care home in Dorset for adults with learning disabilities. Downloaded from: http://www.nationalforum.co.uk/uploads/Audit Report Purbeck Care-Final-10-022015.pdf (Accessed 1.6.15)

Cross, R. M. (2005) Exploring attitudes: the case for Q methodology. Health Education Research, 20, 206-213.

Darton, R., Baumker, T., Callaghan, L., Holder, J., Netten, A. \& Towers, A. M. (2012) The characteristics of residents in extra care housing and care homes in England. Health \& Social Care in the Community, 20, 87-96. 
Davis, M. C., Challenger, R., Jayewardene, D. N. W. \& Clegg, C. W. (2014) Advancing socio-technical systems thinking: A call for bravery. Applied Ergonomics, 45, 171-180.

Department for Communities and Local Government (2008) Lifetime Homes, Lifetime Neighbourhoods. A National Strategy for Housing in an Ageing Society. Department for Communities and Local Government, London.

Derose, K.P. \& Varda, D.M. (2009) Social Capital and Health Care Access: A Systematic Review. Medical Care Research and Review, 66, 272-306.

Eccleston, C., Williams, A. C. D. \& Rogers, W. S. (1997) Patients' and professionals' understandings of the causes of chronic pain: Blame, responsibility and identity protection. Social Science \& Medicine, 45, 699-709.

English Health Service Ombudsman (2011) Care and Compassion: Report of the Health Service Ombudsman on Ten Investigations into NHS Care of Older People. The Stationery Office, London.

Evans, S. \& Vallelly, S. (2007) Never a dull moment? Promoting social well-being in extra care housing, Housing, Care and Support, 10, 14-19.

Fiori, K. L., Antonucci, T. C. \& Akiyama, H. (2008) Profiles of social relations among older adults: a cross-cultural approach. Ageing \& Society, 28, 203-231.

Francis, R. (2013) Report of the Mid Staffordshire NHS Foundation Trust Public Inquiry. Downloaded: from:https://www.gov.uk/government/uploads/system/uploads/attachment_data/file/279 124/0947.pdf (Accessed 9.8.15)

Gallagher, K \& Porock, D. (2010) The Use of Interviews in Q Methodology Card Content Analysis, Nursing Research, 59, 295-300.

Gilson, L. (2003) Trust and the development of health care as a social institution. Social Science \& Medicine, 56, 1453-1468.

Gilson, L. (2006) Trust in health care: theoretical perspectives and research needs. Journal of Health Organization and Management, 20, 359-375.

Girard, M. \& Mullet, E. (1997) Forgiveness in adolescents, young, middle-aged, and older adults. Journal of Adult Development, 4, 209-220.

Gittell, J. H. \& Douglass, A. (2012) Relational Bureaucracy: Structuring Reciprocal Relationships into Roles. Academy of Management Review, 37, 709-733.

Gittell, J. H., Fairfield, K. M., Bierbaum, B., et al. (2000) Impact of relational coordination on quality of care, postoperative pain and functioning, and length of stay - A nine-hospital study of surgical patients. Medical Care, 38, 807-819.

Gittell, J. H., Godfrey, M. \& Thistlethwaite, J. (2013) Interprofessional collaborative practice and relational coordination: Improving healthcare through relationships. Journal of Interprofessional Care, 27, 210-213.

Gittell, J. H., Weinberg, D. B., Bennett, A. L. \& Miller, J. A. (2008) Is the Doctor In? A Relational Approach to Job Design and the Coordination of Work. Human Resource Management, 47, 729-755.

Grimshaw, P., McNichol, E. \& McGowan, L. (2016) Building a system-wide approach to community relationships with the findings of a scoping review in health and social care. Journal of Health Organization and Management. 7, 1047-1062.

Holt-Lunstad, J., Smith, T. B. \& Layton, J. B. (2010) Social Relationships and Mortality Risk: A Metaanalytic Review. Plos Medicine, 7, 1-20.

Humphries, R. \& Curry, N. (2011) Integrating health and social care: where next? Kings Fund, UK.

Jewson N, Jeffers S, Kalra V. (2003) Family care, respite services and Asian communities in Leicester. Final Report. Ethnicity Research Centre and the University of Leicester.

Kline, P. (1994) An easy guide to factor analysis. London: Routledge. 
Knight, C., Haslam, S. A. \& Haslam, C. (2010) In home or at home? How collective decision making in a new care facility enhances social interaction and wellbeing amongst older adults. Ageing \& Society, 30, 1393-1418.

Kodner, D. L. (2006) Whole-system approaches to health and social care partnerships for the frail elderly: an exploration of North American models and lessons. Health \& Social Care in the Community, 14, 384-390.

Lewin, K. (1946) Resolving social conflicts and field theory in social science. American Psychological Association, Washington.

McCabe, T. J. \& Sambrook, S. (2014) The antecedents, attributes and consequences of trust among nurses and nurse managers: A concept analysis. International Journal of Nursing Studies, 51, 815-827.

McCauley, K., Montgomery, P., Mossey, S. \& Bailey, P. (2015) Canadian community mental health workers' perceived priorities for supportive housing services in northern and rural contexts. Health \& Social Care in the Community, 23, 632-641.

McKeown, M., Hinks, M., Stowell-Smith, M., Mercer, D. \& Forster, J. (1999) Q methodology, risk training and quality management. International Journal of Health Care Quality Assurance, 12, 254-266.

Mechanic, D. (1996) Changing medical organization and the erosion of trust. Milbank Quarterly, 74, 171-189.

Meyer, J. (2000) Using qualitative methods in health related action research. British Medical Journal, 320, 178-181.

Mohseni, M. \& Lindstrom, M. (2007) Social capital, trust in the health-care system and self-rated health: The role of access to health care in a population-based study. Social Science \& Medicine, 64, 1373-1383.

Mold, F., Fitzpatrick, J. M. \& Roberts, J. D. (2005) Minority ethnic elders in care homes: a review of the literature. Age and Ageing, 34, 107-113.

Morgan, S. (2013) Risk decision-making: working with risk and implementing positive risk-taking. Pavilion Publishing \& Media, Brighton.

NHS (2014). Five Year Forward View. National Health Service England, U.K.

O'Malley, L. \& Croucher, K. (2005) Housing and dementia care - a scoping review of the literature. Health \& Social Care in the Community, 13, 570-577.

Orrell, A., McKee, K., Torrington, J., et al. (2013) The relationship between building design and residents' quality of life in extra care housing schemes. Health \& Place, 21, 52-64.

Pattison, J. \& Kline, T. (2015) Facilitating a just and trusting culture. International Journal of Health Care Quality Assurance, 28, 11-26.

Peters, D. H. (2014) The application of systems thinking in health: why use systems thinking? Health Research Policy and Systems, 12, 51-57.

Plsek E. \& Wilson T. (2001) Complexity, leadership, and management in healthcare organizations. British Medical Journal, 323, 746-749.

Powell, M., Dawson, J. F., Topakas, A., Durose, J., \& Fewtrell, C. (2014). Staff satisfaction and organisational performance: evidence from a longitudinal secondary analysis of the NHS staff survey and outcome data. Health Services and Delivery Research, 2, 1-336.

Riseborough, M., Fletcher, P. \& Gillie, D. (2015) Extra-Care Housing. What is it in 2015? Housing Learning \& Improvement Network, UK.Robertson, R., Gregory, S. \& Jabbal, J. (2014) The social care and health systems of nine countries. Kings Fund, U.K.

Schmolck, P. (2002) PQMethod (version 2.35) [Computer software]. Downloaded from: http://schmolck.userweb.mwn.de/qmethod/downpqwin.htm

Smith, K.P., Christakis, N.A. (2008) Social Networks and Health. Annual Review of Sociology, 34, 405429.

Stainton Rogers, W. (1991) Explaining Health and IIIness. "An Exploration of Diversity. Harvester Wheatsheaf, Hemel Hempstead. 
Stephenson, W. (1953) The study of behaviour: Q technique and its methodology. Chicago Press, Chicago.

Smith, K. P. \& Christakis, N. A. (2008) Social networks and health. Annual Review of Sociology, 34, 405-429.

Stenner, P. H. D., Cooper, D. \& Skevington, S. M. (2003) Putting the $Q$ into quality of life; the identification of subjective constructions of health-related quality of life using $\mathrm{Q}$ methodology. Social Science \& Medicine, 57, 2161-2172.

Turnbull, J.K (2011). Leadership in Context: Lessons from new leadership theory and current leadership development practice [online]. Downloaded from; www.kingsfund.org.uk/leadershipcommission (Accessed 1.5.16)

United Nations (2013) World Population Ageing. New York. United Nations Publication, New York. van Exel, N. J. A., de Graaf, G. \& Brouwer, W. B. F. (2006) "Everyone dies, so you might as well have fun!" Attitudes of Dutch youths about their health lifestyle. Social Science \& Medicine, 63, 2628-2639.

Walshe, C. \& Luker, K. A. (2010) District nurses' role in palliative care provision: A realist review. International Journal of Nursing Studies, 47, 1167-1183.

Watts, S \& Stenner, P (2005) Doing Q methodology: theory, method and interpretation, Qualitative Research in Psychology, 2, 67-91.

World Health Organisation (2010) The social determinants of health. The Solid Facts Downloaded 12.10.15 from:http://www.euro.who.int/_data/assets/pdf_file/0005/98438/e81384.pdf (Accessed 17.3.16) 
Table 1 Factor matrix with an * indicating a 'defining sort'

\begin{tabular}{|c|c|c|c|c|c|c|}
\hline & QSORT PP & F1 & F2 & F3 & F4 & F5 \\
\hline 1 & 2FCSLM & 0.0247 & 0.209 & -0.0505 & $0.3780^{*}$ & 0.3459 \\
\hline 2 & 5FASHS & $0.5919^{*}$ & -0.0137 & 0.1747 & 0.1281 & 0.3652 \\
\hline 3 & 6FCSHM & $0.4687^{*}$ & -0.1066 & $0.4354^{*}$ & $0.5138^{*}$ & 0.1173 \\
\hline 4 & 7FF1LD & 0.1663 & $0.386^{*}$ & -0.0674 & 0.0393 & -0.088 \\
\hline 5 & 8FD1LD & 0.1601 & 0.1939 & 0.2863 & $0.4530^{*}$ & -0.3274 \\
\hline 6 & 9ME2LS & 0.0592 & $0.4460^{*}$ & $0.5905^{*}$ & 0.163 & 0.1981 \\
\hline 7 & 10MG1LM & $0.5404^{*}$ & -0.0212 & 0.3346 & 0.0198 & 0.2705 \\
\hline 8 & 11FG1LM & $0.4862^{*}$ & 0.1643 & 0.3671 & -0.0477 & -0.0038 \\
\hline 9 & 13MD2LS & 0.0772 & 0.0712 & -0.1132 & -0.1485 & $0.5549^{*}$ \\
\hline 10 & 14FCFLM & $0.6559^{*}$ & 0.1437 & 0.1439 & 0.2142 & 0.0972 \\
\hline 11 & 15MCTH & -0.0245 & 0.0577 & 0.1 & $0.4870^{*}$ & -0.0716 \\
\hline 12 & 17FDFLM & $0.4660^{*}$ & -0.1111 & 0.0447 & $0.4525^{*}$ & -0.1397 \\
\hline 13 & 18FDFLM & 0.378 & -0.0043 & $0.4768^{*}$ & 0.1573 & 0.1236 \\
\hline 14 & 19FAPLS & $0.4993^{*}$ & 0.2341 & $0.4259^{*}$ & 0.1402 & $0.4183^{*}$ \\
\hline 15 & 20MBSLM & $0.5479^{*}$ & 0.2883 & 0.0365 & 0.2067 & 0.2851 \\
\hline 16 & 21FCSLM & $0.3962^{*}$ & 0.2507 & -0.1939 & 0.1365 & -0.0261 \\
\hline 17 & $22 \mathrm{FCTH}$ & -0.0922 & -0.0537 & 0.1994 & 0.0304 & $0.5558^{*}$ \\
\hline 18 & 23FCTH & $0.3845^{*}$ & 0.2936 & 0.0084 & 0.2076 & 0.2064 \\
\hline 19 & 24MDPHM & -0.1124 & $0.6769^{*}$ & -0.0244 & 0.3722 & 0.1599 \\
\hline 20 & 25FAPLS & $0.4669^{*}$ & 0.0304 & $0.4743^{*}$ & -0.142 & 0.103 \\
\hline 21 & 26FCTH & 0.2616 & $0.6751^{*}$ & 0.2364 & -0.0352 & -0.1206 \\
\hline 22 & 27FF2HW & -0.0152 & 0.0264 & $0.4903^{*}$ & 0.1389 & -0.0984 \\
\hline 23 & 28FBPH & $0.3825^{*}$ & 0.1384 & 0.0431 & $0.4304^{*}$ & 0.2915 \\
\hline 24 & 29FBPM & $0.5301^{*}$ & 0.0146 & -0.0421 & 0.0002 & -0.1227 \\
\hline 25 & 30FBSL & $0.6154^{*}$ & 0.1861 & 0.1287 & 0.0639 & -0.0359 \\
\hline 26 & 31FEFLM & $0.7717^{*}$ & 0.1265 & 0.098 & -0.1009 & -0.1878 \\
\hline \multirow[t]{2}{*}{27} & 32FDTH & 0.09 & $0.5914^{*}$ & 0.2674 & -0.0828 & 0.2684 \\
\hline & Eigenvalues & 6.4348 & 1.7571 & 1.3508 & 1.3383 & 1.2575 \\
\hline
\end{tabular}


Table 2 Relational statement matrix (including organising relational themes and socio-technical categories) showing Q sort statement descriptions and Factor Scores(1-5)

\begin{tabular}{|c|c|c|c|c|c|c|c|c|}
\hline \multirow{2}{*}{$\begin{array}{l}\text { Q Sort } \\
\text { No. }\end{array}$} & \multicolumn{2}{|c|}{ Relational statement matrix } & \multirow[b]{2}{*}{ Q Sort Statement } & \multirow[b]{2}{*}{ Factor1 } & \multirow[b]{2}{*}{ Factor 2} & \multirow[b]{2}{*}{ Factor 3} & \multirow[b]{2}{*}{ Factor 4} & \multirow[b]{2}{*}{ Factor 5} \\
\hline & Socio-Technical & Relational themes & & & & & & \\
\hline 1 & Culture & Trust & People will sometimes take risks to help each other & -5 & 0 & -2 & -5 & 0 \\
\hline 2 & People & Trust & Families or carers get on well with staff & 3 & 1 & 1 & 5* & $-3 *$ \\
\hline 3 & Process & Respect & There are opportunities to begin activities with others inside the unit & -1 & 1 & 1 & 0 & 1 \\
\hline 4 & Infrastructure & Trust & There are opportunities to begin activities with others outside the unit & -2 & 0 & 1 & -1 & 2 \\
\hline 5 & Culture & Compassion & Everyone works together to get things done & 0 & 2 & 2 & 2 & -2 \\
\hline 6 & Culture & Trust & Everyone has an opportunity to help others & -1 & $-4^{*}$ & 0 & -1 & 2 \\
\hline 7 & Culture & Compassion & Everyone is generally open and honest & 2 & 0 & 1 & -1 & 0 \\
\hline 8 & People & Integrity & Residents see the same staff everyday & $4 *$ & -3 & -1 & 0 & 1 \\
\hline 9 & People & Fairness & There are others around who share the same background & -3 & 0 & -3 & 0 & 1 \\
\hline 10 & People & Trust & Different people can take the lead when things go wrong & -2 & 0 & 0 & -2 & 0 \\
\hline 11 & Process & Trust & When things go wrong people feel there is always someone tell & 4 & -1 & 3 & 3 & 1 \\
\hline 12 & Culture & Trust & When something goes wrong someone is found to blame & -4 & -5 & -5 & -5 & -5 \\
\hline 13 & People & Trust & The people around the unit have each other's best interests in mind & 2 & 2 & 0 & -3 & -4 \\
\hline 14 & Process & Integrity & There are lots of questions and discussions about how to improve things & 0 & -1 & -1 & 1 & 0 \\
\hline 15 & People & Fairness & People will challenge each other if they think something is wrong & -4 & -1 & -3 & 0 & -3 \\
\hline 16 & Process & Compassion & When arguments or fall outs happen there is a clear way of sorting things out & 0 & -3 & 0 & 2 & -1 \\
\hline 17 & Culture & Integrity & Staff share the same idea of 'how things should work around here & -1 & -4 & -2 & -4 & 1 \\
\hline 18 & Culture & Integrity & If others say they will do something they generally do & -1 & 0 & -1 & -3 & 2* \\
\hline 19 & Process & Integrity & Residents only have to tell staff things once & $-3^{*}$ & -2 & -1 & -2 & -1 \\
\hline 20 & People & Compassion & People are prepared to give and take when they disagree & -2 & -3 & $-4^{*}$ & -2 & -1 \\
\hline 21 & Infrastructure & Respect & Residents have a lot of say over their personal environment & 1 & 1 & 0 & 1 & $5^{*}$ \\
\hline 22 & Process & Trust & Residents expectation of their future is shared by the staff & -2 & 1 & -4 & -3 & -3 \\
\hline 23 & Infrastructure & Integrity & There are a number of different areas where everyone can go and mix with others & 0 & -2 & 3 & 2 & 4 \\
\hline 24 & People & Integrity & There is the right mix of skills amongst the staff & 2 & -2 & 0 & 3 & 1 \\
\hline 25 & Infrastructure & Integrity & Residents can contact family and friends when they like & 4 & 1 & 4 & 3 & 2 \\
\hline
\end{tabular}




\begin{tabular}{|c|c|c|c|c|c|c|c|c|}
\hline 26 & Process & Integrity & Everyday activities are carefully planned & 0 & -4 & -2 & 0 & -2 \\
\hline 27 & Culture & Compassion & People have the time to talk and listen and share stories & 0 & 0 & -1 & $4^{*}$ & -1 \\
\hline 28 & People & Compassion & Everyone is treated as a whole person & 5 & 2 & 1 & 3 & 4 \\
\hline 29 & Process & Compassion & A constant effort is made by others to help residents to feel at home & 3 & 0 & 4 & 4 & $-3 *$ \\
\hline 30 & Infrastructure & Compassion & People get pleasure from being with other residents and staff & 2 & -1 & 2 & 4 & 0 \\
\hline 31 & Culture & Fairness & Families friends or carers are able to contribute to decisions that affect the residents & 3 & 1 & 2 & 2 & $-4^{*}$ \\
\hline 32 & Process & Compassion & When someone is new a lot of effort is made to help them to settle in & 2 & 4 & 5 & 5 & $-1^{*}$ \\
\hline 33 & Culture & Fairness & Everyone is treated as equals & 5 & 3 & 4 & 2 & 3 \\
\hline 34 & Process & Fairness & People are involved in all decisions that affect them & 1 & 4 & 3 & 1 & 3 \\
\hline 35 & Process & Fairness & Everyone could change the rules if they really tried & -5 & -2 & -5 & -4 & -2 \\
\hline 36 & Process & Fairness & Residents know why decisions that affect them are made & 0 & -1 & -1 & 0 & $5^{*}$ \\
\hline 37 & People & Trust & People should feel they can freely express their emotions & 1 & 3 & 5 & 0 & -2 \\
\hline 38 & Process & Fairness & Residents understand how things get done around the unit & -2 & -3 & -2 & -3 & $2 *$ \\
\hline 39 & Culture & Respect & Residents are addressed in an appropriate way e.g. $\mathrm{Mr} / \mathrm{Mrs}$ & 1 & 2 & -2 & -4 & 0 \\
\hline 40 & People & Respect & Others recognise the things people want to achieve in the future & -3 & -1 & -4 & $1^{*}$ & -2 \\
\hline 41 & Culture & Respect & Peoples culture and traditions are respected & 0 & 3 & 2 & -1 & 0 \\
\hline 42 & Infrastructure & Fairness & Residents have regular access to the telephone or internet & -3 & -2 & $3^{*}$ & -1 & 0 \\
\hline 43 & Process & Integrity & The organisation has very strong rules and procedures & 1 & -5 & -3 & 0 & -5 \\
\hline 44 & Culture & Respect & Everyone's age is respected & 1 & $5^{*}$ & 1 & -2 & -1 \\
\hline 45 & People & Respect & Residents previous life achievements are recognised by others & -4 & $4^{*}$ & -3 & $1^{*}$ & -4 \\
\hline 46 & People & Respect & Everyone has the opportunity to contribute their skills or knowledge & -1 & 5 & 0 & -1 & 3 \\
\hline 47 & Infrastructure & Respect & People respect each other's privacy & 3 & 2 & 2 & $-2 *$ & 4 \\
\hline 48 & Infrastructure & Fairness & Residents have easy access to the local community & -1 & 3 & 0 & 1 & 3 \\
\hline
\end{tabular}

Significant loadings $(p<0.01)$ are indicated with asterisk $\left(^{*}\right)$

Table to shows the comparative rankings given to each item (statement) within each of the 5 extracted factors. For example, Factor 1 ranks statement 1 at 5 and statement 2 and +3 . Each row indicates how the statement was ranked across all 5 extracted factors. 


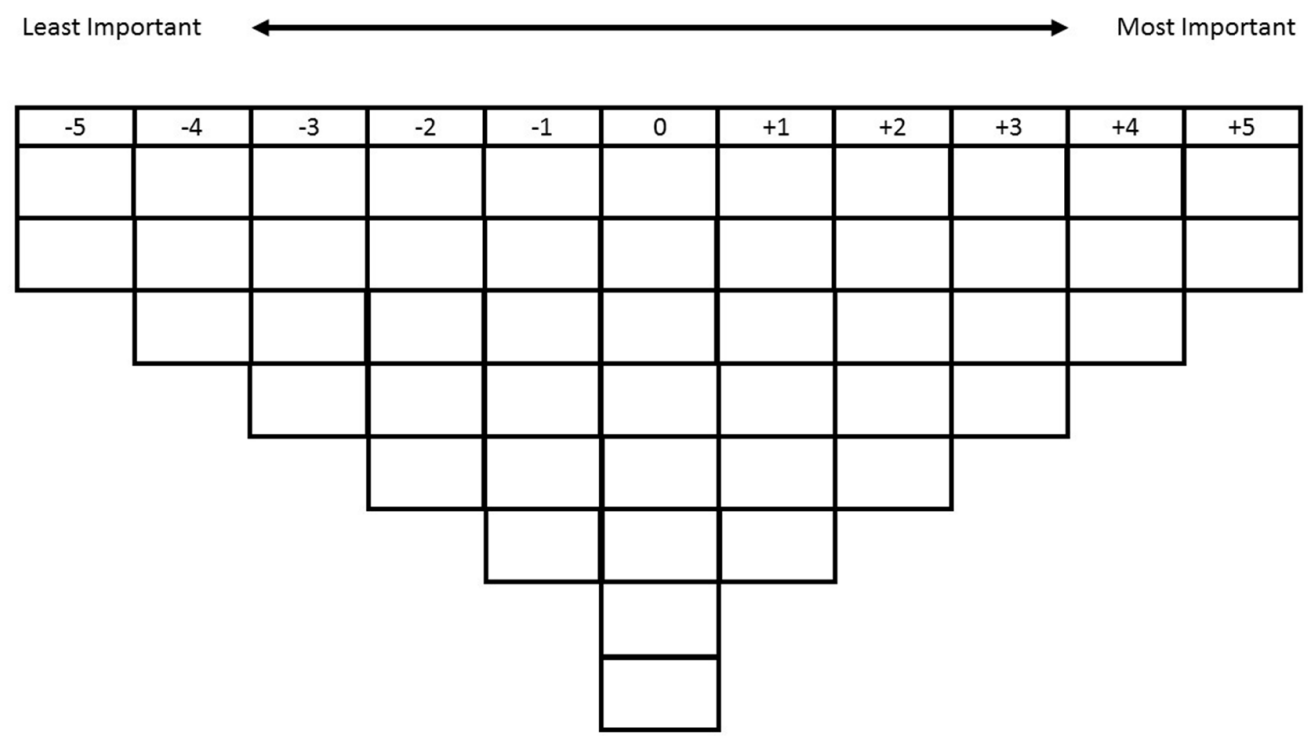

Figure $1 Q$ sort grid pattern for placement of individual statement cards 